\title{
EL RECURSO DE AMPARO ECONÓMICO EN LA JURISPRUDENCIA (1990-1995)
}

\author{
ENRIQUE NAVARRo BELTRÁN \\ Profesor Asistente de Derecho Constitucional \\ Facultad de Derecho - Universidad de Chile
}

La presente ponencia pretende sintetizar algunos aspectos abordados por la jurisprudencia de nuestros tribunales en relación al recurso de amparo económico durante el quinquenio 1990 a 1995.

\section{ANTECEDENTES DEL RECURSO DE AMPARO ECONÓMICO ${ }^{1}$}

1. El artículo único de la Ley $N^{o} 18.971$ (Diario Oficial de 10.3.1990) establece:

"Cualquier persona podrá denunciar las infracciones al artículo 19, número 21, de la Constitución Política de la República de Chile.

$\mathrm{El}$ actor no necesitará tener interés actual en los hechos denunciados.

La acción podrá intentarse dentro de seis meses contados desde que se hubiere producido la infracción, sin más formalidad ni procedimiento que el establecido para el recurso de amparo, ante la Corte de Apelaciones respectiva, la que conocerá de ella en primera instancia. Deducida la

*Abreviaturas usadas. CEP: Revista del Centro de Estudios Públicos. RDE: Revista de Derecho Económico (U. de Chile). FM: Revista Fallos del Mes. GJ: Gaceta Jurídica. JDP: Jornadas de Derecho Público. P: Política (U. de Chile). RCHD: Revista Chilena de Derecho (U. Católica). RD: Revista de Derecho (U. Concepción). RDJ: Revista de Derecho y Jurisprudencia. RDP: Revista de Derecho Público (U. de Chile). RDV: Revista de Derecho (U. Católica de Valparaíso). TD: Temas de Derecho (U. Gabriela Mistral).

${ }^{1}$ Sobre el tema vid. P. Varas A., Amparo Económico, RDP (1991), 45-70; E. Soto Kloss, Amparo económico y rol subsidiario del Estado, TD 7 (1993), 105 ss.; F. Zúñiga, Constitución y amparo económico; GJ 145 (1992) 10; I. Aróstica, Acción de amparo económico. Acerca del recurrente y el recurrido, GJ 182 (1995) 7-14.

Revista de Derecho Público

vol. $1995\left(\mathrm{~N}^{\mathrm{os}} 57-58\right)$ 
acción, el tribunal deberá investigar la infracción denunciada y dar curso progresivo a los autos hasta el fallo respectivo.

Contra la sentencia definitiva, procederá el recurso de apelación, que deberá interponerse en el plazo de cinco días, para ante la Corte Suprema y que, en caso de no serlo, deberá ser consultada. Este tribunal conocerá el negocio en una de sus salas.

Si la sentencia estableciere fundadamente que la denuncia carece de toda base, el actor será responsable de los perjuicios que hubiere causado".

2. El artículo primitivamente se encontraba dentro de un proyecto de ley que regulaba la actividad y participación productiva del Estado y sus organismos

En el proyecto se contemplaban normas generales aplicables a toda legislación sobre actividad empresarial desarrollada por el Estado, el recurso de amparo económico para hacer efectiva la garantía constitucional de la libertad económica y se fijaba el ámbito empresarial del Estado.

3. Finalmente se transformó en un articulo único, desvinculándose del resto del proyecto ${ }^{2}$

4. Características del recurso de amparo económico:

a) Naturaleza jurídica: es una acción pública, en donde el actor no necesita tener un interés actual en los hechos denunciados.

b) Propósito: denunciar las infracciones a la garantía establecida en el art. 19 № 21 de la Constitución Política del Estado.

c) Plazo para su interposición: 6 meses contados desde que se produjo la referida infracción.

d) Tribunal competente: la Corte de Apelaciones respectiva.

e) Principio formativo del procedimiento: rige el principio inquisitivo, de manera que el tribunal debe investigar la infracción denunciada y dar curso progresivo a los autos hasta el fallo respectivo.

f) Normas sobre tramitación: se aplican las del recurso de amparo, con la salvedad que el plazo para apelar de la sentencia dictada por la Corte de Apelaciones es de 5 días y que, en caso de no interponer dicho recurso, procede el trámite de la consulta.

${ }^{2}$ La Ley № 18.965 (10-03-1990) fijó ciertas normas relativas a los derechos del Estado en materia empresarial. 
g) Responsabilidad civil: si la sentencia establece fundadamente que la denuncia carece de toda base el actor puede ser responsable de los daños y perjuicios.

\section{BIEN JURÍDICO PROTEGIDO: ARTÍCULO 19 № 21}

\section{Disposición constitucional}

El artículo 19 № 21 de la Constitución Política de la República de Chile, correspondiente a una de las garantías que conforman el denominado orden público económico ${ }^{3}$, asegura a todas las personas:

"El derecho a desarrollar cualquier actividad económica que no sea contraria a la moral, al orden público o a la seguridad nacional, respetando las normas legales que la regulen".

"El Estado y sus organismos podrán desarrollar actividades empresariales o participar en ellas sólo si una ley de quórum calificado los autoriza. En tal caso, esas actividades estarán sometidas a la legislación común aplicable a los particulares, sin perjuicio de las excepciones que por motivos justificados establezca la ley, la que deberá ser, asimismo, de quórum calificado".

${ }^{3}$ Sobre Orden Público Económico vid. P. Barahona U., Fuentes de la insititucionalidad económica, Vigilia № 13 (Sep., 1978); José Luis Cea E., El orden público en la nueva Constitución, en Seminario de Estudio sobre la Constitución Política del Estado de 1980; el mismo Notas sobre el orden público económico, G.J. 135 (1991) 18-32; F. Dougnac R., La garantía constitucional del $N^{\circ} 21$ del artículo 19 de la Constitución en relación con las demás que configuran el orden público económico, G.J. 68 (1986) 6-12, R. Guerrero, La Constitución económica, RCHD 6 № 1-4 (1979), José T. Hurtado C., El orden público económico en la Constitución de 1980, Colección de Seminarios. Facultad de Derecho U. de Chile (1981) 101 y ss.; A. Irarrázabal C., Principios económicos de la Constitución de 1980, RCHD 14 (1987) 97-115; R. Lüders, Economia y nueva institucionalidad, Vigilia № 9 (mayo, 1978); L. Montt D., Orden príblico económico y economía social de mercado: elementos para una formulación constitucional, RDE 41 (1978); J. Reyes R., El Estado como regulador, mediante ley, del ejercicio de los derechos fundamentales y de contralor de dicha normativa, RCHD 20 (1993) 69-91; R. Sandoval L., Acerca del orden público económico, RD 188 (1990) 107-117. 


\section{Garantías constitucionales reguladas en el artículo $19 N^{\circ} 21$}

a) Libertad para desarrollar cualquier actividad económica ${ }^{4}$

La Constitución garantiza a todos los ciudadanos, como consecuencia del principio fundamental de la libertad e igualdad de los hombres en dignidad y derechos -consagrada en el artículo 1 de la norma fundamental-el derecho a desarrollar cualquier actividad económica enmarcada dentro de los límites esenciales, cuales son: la moral, el orden público y la seguridad nacional, respetando las normas legales que las regulen.

b) Estado empresarial ${ }^{5}$

Como consecuencia del principio de subsidiariedad, la norma constitucional restringe el ámbito de posibilidades de actuación del Estado en materia empresarial o de participar en la actividad económica sólo si una ley de quórum calificado lo autoriza, sometiéndose en tal caso a la legislación común

${ }^{4}$ Sobre la libertad para desarrollar cualquier actividad económica vid. L. Bulnes A., El derecho a desarrollar cualquier actividad económica, en RDP $37-38$ (1985) 149-165; G. Bruna C., La libertad económica elemento de un nuevo orden político, P 13 (1987) 59-76; R. Huidobro S., El derecho a desarrollar cualquier actizidad económica en las Actas de la Comisión de Estudios de la nueva Constitución, RDP 43-44 (1988), 98-116.

${ }^{5}$ Sobre el Estado Empresarial vid. R. Bertelsen R., El estado empresario en la constitución de 1980, RCHD 14 (1987) 115-126; J. Carmona P., Análisis del proyecto elaborado por la Comisión de Estudios de las leyes orgánicas constitucionales, P 13 (1987) 29-46; M. Collados N., El rol del Estado en economia, P 13 (1987) 77-88; F. Cumplido C., Reflexiones sobre el anteproyecto de ley que regula la actividad empresarial del Estado y sus organismos, RCHD 14 (1987) 141 ss.; M. Feliú J., El Estado y la empresa privada, P 13 (1987) 47-58; R. García R., El rol del Estado en materia empresarial, P 13 (1987), 19-28; G. Larroulet V., Visión del gobierno sobre el Estado empresario, RCHD 14 (1987) 157 y ss.; el mismo, Reflexiones en torno al Estado empresario en Chile, CEP 14 (1984); J. López B., Algunas consideraciones jurídicas sobre el desarrollo del Estado, TD 9 № 1 (1994) 87-103; O. Muñoz G., Visión del Estado empresarial en Chile, RCHD 14 (1987) 187-192; P. Pierry A., Algunos aspectos de la actividad empresarial en Chile, RDP $37-38$ (1985) 219-239; J. Precht P., El estado empresario: análisis de la legislación complementaria constitucional, G.J. 80 (1987) 13-24; el mismo, Empresas Municipales y Estado empresario, G.J. 86 (1987) 8 y ss.; E. Tironi B., Otro rol para el Estado de Chile: de subsidiario a promotor, RCHD 14 (1987) 171-186; S. Undurraga, Empresas estatales en la economia, RCHD 14 (1987), 193-198; C. Urenda Z., El Estado empresario: visión de un abogado, RCHD 14 (1987) 147-156. 
aplicable a los particulares, sin perjuicio de las excepciones que por motivos justificados establezca la misma ley de quórum calificado.

Debe señalarse, en todo caso, que la propia Constitución establece normas excepcionales que autorizan al Estado actuar en materia empresarial: en la Gran Minería del Cobre, a través de Codelco (artículo 3 transitorio); en la exploración y explotación de sustancias minerales no concesibles (artículo $19 \mathrm{~N}^{\circ} 24$ inciso $10^{\circ}$ ) y, finalmente, en materia de estaciones de televisión (artículo $19 \mathrm{~N}^{\mathrm{o}} 12$ inciso $5^{\circ}$ ).

\section{ANÁLISIS JURISPRUDENCIAL}

A. Algunos aspectos analizados por la jurisprudencia

\section{Naturaleza jurídica de la acción}

"Se trata de una acción jurisdiccional de carácter conservadora, especial y popular, en que el actor no necesita tener interés actual en el recurso" ${ }^{\text {. }}$

\section{Bien jurídico tutelado}

2.1. Concepto de orden público económico

"Conjunto de principios y normas jurídicas que organizan la economía del país y facultan a la autoridad para regularla"7.

"Conjunto de principios y normas jurídicas que organizan la economía de un país y facultan a la autoridad para regularla en armonía con los valores de la sociedad nacional que formula la Constitución Política"8.

2.2. Objetivo: Protege el inciso $2^{\circ}$ del art. 19 № 21 (Estado empresarial)

"Debe entenderse creado para proteger otras situaciones cubiertas por el artículo 19 № 21 del texto constitucional, como es la que se contempla en su inciso segundo"g.

${ }^{6}$ Comercial Agropecuaria Menichetti con Banco del Estado (rol 3.899-94), 26-01-1995, GJ 177, 20; en RDJ 92 (1995) 2.5, 18-23.

${ }^{7}$ Entel con CTC (rol 2762-91), 15-06-1992, GJ 144, 74.

${ }^{8}$ Comercial Agropecuaria Menichetti, cit. nota 6.

${ }^{9}$ Enrique Llano con Seremi Metropolitano de Transporte (rol 785-91), 17-4-1991, GJ 130,41 . 
"Este recurso especial está relacionado con el derecho del Estado y sus organismos para desarrollar actividades empresariales o participar en ellas, sólo si una ley de quórum calificado los autoriza; en otras palabras se refiere a lo establecido en el inciso segundo del artículo 21. Por consiguiente no se relaciona con el inciso primero del referido artículo que protege el derecho a desarrollar cualquier actividad económica, que de conformidad a lo establecido en el artículo 20 de la carta fundamental, está resguardado por el recurso de protección"10.

"El recurso de amparo especial establecido en el artículo único de la ley № 18.971, ha sido establecido para resguardar el orden público económico cuando el Estado y sus organismos entran a desarrollar, sin contar con una autorización legal especial, actividades empresariales o participando en éstas"1l.

Cambio de criterio reciente: protege los dos incisos del art. 19 № 21 (también la libertad económica)

"La acción de amparo fue creada con el objeto de cautelar la garantía constitucional de la libertad económica que consagra el artículo 19 de la Constitución Política en ambos incisos de su número 21... Del tenor literal claramente manifestado en el texto de la Ley $\mathrm{N}^{\mathrm{o}}$ 18.971, aparece que el recurso ampara la garantía constitucional estableciendo acción popular para denunciar todas las infracciones a dicha norma constitucional, ya que no hace distinciones entre sus dos incisos" 12 .

"Que la Ley № 18.971 estableció el recurso especial de amparo, para denunciar las infracciones al artículo 19 № 21, de la Constitución Política de la República de Chile, sin hacer distinción alguna entre las diversas situaciones planteadas en ambos incisos del señalado № 21; que frente a lo expresado en el considerando anterior, las argumentaciones vertidas por la recurrida para concluir que el amparo económico sólo es procedente cuando se ha producido una infracción al inciso segundo del artículo $19 \mathrm{~N}^{0} 21$ de la Carta Fundamental, no llevan al convencimien to de esta Corte en cuanto que así deba resolverlo, variando por lo demás con ello la jurisprudencia estable-

${ }^{10}$ Asociación Gremial de Armadores Artesanales VIII Región con Presidente de la Repuiblica (rol 738-92), 6-5-1992, GJ 143, 63.

${ }^{11}$ Compañía Minera Santa Laura con Municipalidad de San Bernardo (rol 120-95), 23-10-95, GJ 186, 139.

${ }^{12}$ Comercial Agropecuaria Menichetti, cit., nota 6. 
cida por esta sala especializada, cuando resolvió el recurso de amparo económico № 24.513, el 28 de marzo último"12 bis.

2.3. Dentro del concepto de "normas legales", señalado en el artículo 19 № 21, debe incluirse la potestad reglamentaria

"Esta última expresión ('las normas legales que la regulen') debe tomarse en sentido amplio, esto es, incluyendo ordenanzas y resoluciones de carácter general dictadas por el Municipio en conformidad a la ley"13.

"Que esta Corte concuerda con otorgar a la expresión "normas legales" una extensión amplia y comprensiva de las normas emitidas por la autoridad potestativa del órgano administrativo del Estado"14.

\subsection{Concepto de actividad empresarial}

"Fundación de una casa o sociedad mercantil o industrial, ya que tales expresiones aluden claramente a establecimientos cuya finalidad es hacer de los negocios (consiguientemente de las utilidades económicas) el objetivo principal y permanente de su quehacer"15.

\section{Aspectos procedimentales}

3.1. Exclusividad del recurso e improcedencia si se han iniciado otras acciones (por aplicación de las normas del recurso de amparo establecidas en el Código de Procedimiento Penal):

"Corresponde declarar inadmisible aquel recurso interpuesto contra los recurridos en un recurso de protección previo y ya resuelto desfavorablemente, en razón de que la ley se remite a la tramitación del recurso de amparo"16.

"Que en las circunstancias expresadas, la recurrente ha pretendido, por la interposición de dos recursos diferentes, impugnar, por una

${ }^{12 b i s}$ Endesa con Dirección General de Aguas (rol Corte Suprema 35.502-95), 10.1.1996, GJ 187, 49; idéntico Emeres con Municipalidad de Til-Til (rol 1.929-95), 24.11.1995, GJ 187, 54 .

${ }^{13}$ Galleani Rodríguez con Municipalidad de Recoleta (rol 191-94), 30-3-1994, RDJ 91, 2.5, 140-144 (comentario E. Soto Kloss).

${ }^{14}$ Entel con CTC, vid., nota 7.

${ }^{15}$ Merza S.A. con Subsecretario de Pesca y Alcalde Santiago (rol 2.798-94), 4-7-1995, GJ 181,55 .

${ }^{16}$ Achima con Seremis del País (rol 3440-93), 16-5-1994, GJ 167, 58; en RDJ 91.2.5, 209-210 nota (comentario E. Soto Kloss). 
misma infracción al № 21 del artículo 19 de la Constitución Política del Estado... colocando a este tribunal en la posibilidad de dictar dos resoluciones contradictorias entre sí y además avocarse el conocimiento de una causa o negocio pendiente ante otros juzgadores, contraviniendo, de esta manera, en forma manifiesta uno de los principios fundamentales de la organización judicial contenido en el Código Orgánico de los Tribunales" ${ }^{17}$.

"No puede prosperar si ya existe un procedimiento jurisdiccional, respecto del cual existen recursos ordinarios y extraordinarios" 18 .

Cambio de criterio reciente: Sin embargo, cabe hacer presente que la Sala Constitucional de la Corte Suprema, en fallo de 19 de diciembre de 1995, eliminó en un recurso de amparo económico un considerando de la Corte de Apelaciones de Iquique que señalaba la aplicación de las normas del amparo penal al amparo económico, por lo que la referencia sólo debe entenderse en relación al procedimiento mismo. El considerando eliminado expresaba que: "Al amparo económico resulta plenamente aplicable el artículo 306 del Código de Procedimiento Penal, en cuanto él es procedente siempre que no se hubieran deducido otros recursos legales"19.

\subsection{Debe desecharse si existen otras vías jurisdiccionales.}

"Que en una situación como la que plantea el recurrente no puede caber duda de que el medio legal de defensa que corresponde es el recurso de protección..."20.

"Conforme al caso planteado sólo cabe concluir que la acción procesal que corresponde es el recurso de protección"21.

\subsection{Cómputo del plazo (aplicación de normas del Código Civil)}

"Por aplicación del artículo 48 del Código Givil, en cuanto al

${ }^{17}$ Compañia Minera Santa Laura, cit., nota 11.

${ }^{18}$ Ricardo González Fernández con Jefe del Departamento de Propiedad Industrial (rol 3739-90) 27-8-1990, GJ 122, 45.

${ }^{19}$ Grimaldi con Zofri (rol 34552), 27-11-1995, GJ 186, 37.

${ }^{20}$ Enrique Llano, cit., nota 9.

${ }^{21}$ Asociación Gremial de Armadores Artesanales cit., nota 10. Sin embargo se han deducido recursos de amparo económico juntamente con la acción de protección sin que haya habido declaración de inadmisibilidad del primero, ello en atención al principio de especialidad. 
cómputo de los plazos, el recurso aparece presentado en forma extemporánea"22.

\section{No deben someterse materias de lato conocimiento}

"La indemnización que debe pagarse a una empresa por la imposición de paso de energía eléctrica, constituye un conflicto que debe solucionarse ante el tribunal competente y conforme a las normas legales que sean aplicables a la situación correspondiente"23.

"Parece claro que el recurso de amparo económico no sería el procedimiento adecuado para obtener el cumplimiento de las obligaciones emanadas de tal contrato, ya que ello requeriría dilucidar una serie de cuestiones de hecho que precisan de prueba adecuada, imposible de producir en éste y, además, ello se encontraría muy distante de las finalidades específicas por él perseguidas, según se desprende tanto de su letra como de la historia fidedigna de su establecimiento" ${ }^{\text {24 }}$.

\section{Infracción debe fundarse en hechos reales}

"La infracción defe fundarse en hechos reales, efectivos, concretos y determinados y no en simples amenazas de perturbación" 25 .

\section{B. Sujetos pasivos}

Diversas personas naturales o jurídicas particulares han presentado los recursos de amparo económico tanto contra entidades de la administración del Estado (centralizada o descentralizada) como contra particulares. Así por ejemplo:
a) Órganos centralizados: Jefe de Departamento de Propiedad Industrial, Seremi de Transporte, Ejército de Chile, Presidente de la República, Casa de Moneda, Dirección General Aeronáutica y Subsecretaría de Pesca.
b) Órganos descentralizados: Municipalidades de El Tabo, Santiago, Reco- leta y San Bernardo; Codelco; Banco del Estado y Sociedad Zona Franca de Iquique S.A.
c) Particulares: Endesa, CTC.

${ }^{22}$ Grimaldi cit., nota 19.

${ }^{23}$ Pullinque con Endesa (rol 5770-91), 19-3-1992.

${ }^{24}$ Merza S.A., cit., nota 15.

${ }^{25}$ Asimet con Codelco (rol 575-93), 28-4-1993, RDJ 90, 2.5, 157-164. 


\section{Resumen de sentencias judiciales}

\section{Sentencias que han acogido el recurso (Doctrina)}

1.1. Asociación Gremial de Impresores de Chile contra Ejército de Chile

"El Instituto Geográfico Militar debe abstenerse de realizar trabajos de impresión gráfica a terceros, que no pertenezcan al área propia de su especialidad, determinada en su ley orgánica" ${ }^{26}$.

\subsection{Comercial Agropecuaria Menichetti contra Banco del Estado}

"La conducta del Banco del Estado de Chile al retener indebidamente dineros de un mandante para seguridad jurídica de una operación crediticia en que tiene interés, debe ser calificada de arbitraria y atentatoria al derecho garantizado por el № 21 del art. 19 de la Constitución"27.

\subsection{Emeres contra Municipalidad de Til Til}

"La I. Municipalidad de Til Til al prohibir en términos generales la instalación en su comuna de plantas de tratamiento de residuos sólidos de origen domiciliario, rellenos sanitarios y demás actividades que indica el decreto $\mathrm{N}^{\circ}$ 60/95, de 6 de junio de este año, sin consultar previamente a los demás organismos que por la ley tienen injerencia en la materia, ha infringido el artículo $19 \mathrm{~N}^{\circ} 21$ inciso $1^{\circ}$ de nuestra Carta Fundamental, por cuanto la citada actividad no es contraria a la moral, al orden público o a la seguridad nacional, lo que no significa que un proyecto específico sobre la materia a desarrollarse en un determinado lugar pueda ser rechazado por contravenir la normativa constitucional, legal y reglamentaria a la que debe someterse de acuerdo a la naturaleza de la actividad proyectada"28.

2. Algunas sentencias que han rechazado el recurso, por razones

de fondo (Doctrina)

2.1. Conducta en materia de telecomunicaciones

"La transgresión o falta de aplicación por una de las empresas concesionarias (telefónicas) en su relación comercial con otra de dichas

${ }^{26}$ Asociación Gremial de Impresores de Chile con Ejército de Chile (rol 2396-91), 5-12-1991, GJ 138, 59.

${ }^{27}$ Comercial Agropecuaria Menichetti, cit., nota 6.

${ }^{28}$ Emeres, cit., nota 12 bis. 
empresas, no ha impedido a la recurrente, afectada por la conducta de su contratante, el derecho de su actividad económica; como tampoco ha infringido el orden público económico en el sentido que el propio recurrente ha invocado como fundamento de su recurso" ${ }^{" 29}$.

\subsection{Actividades empresariales de la Casa de Moneda}

"Las actividades que desarrolla la Casa de Moneda, destinadas a aumentar su capacidad productiva en la elaboración y comercialización tanto de cospeles como de monedas acuñadas, por ser de su propia especialidad, queda comprendida en la competencia que su ley orgánica le asigna y, en consecuencia, al ejecutarlas no se ha infríngido el artículo $19 \mathrm{~N}^{\circ} 21$, inciso $2^{\circ}$ de la Constitución Política de la República" ${ }^{30}$.

2.3. Negativa para obtener patente alcohólica

"No existe impedimento, traba u obstáculo para ejercer una actividad económica lícita, si el Alcalde de una Municipalidad niega el otorgamiento de una patente para el expendio de bebidas alcohólicas de un local, en razón de encontrarse éste a una distancia menor que aquella que exige la ley para su instalación, respecto de ciertos servicios públicos o establecimientos que, al efecto indica, por motivos de bien común"31.

2.4. Asociación de Codelco con empresa extranjera

"La actividad de Codelco, al vincularse con una empresa extranjera para formar una sociedad anónima, cuyo objetivo queda comprendido dentro de las facultades que a aquélla le otorga la ley para el cumplimiento de sus finalidades, no puede por sí sola constituir infracción al artículo 19 № 21 de la Constitución Política de la República y que motiva el presente recurso de amparo económico, mientras esa sociedad no realice actividades que resulten ajenas al objeto social de Codelco, definido en el artículo $3^{\circ}$ del DL 1.350 de $1976^{\prime 32}$.

2.5. Normativa para comercio estacionario

"La sola exclusión de la venta de ciertas prendas de vestir para

${ }^{29}$ Entel con CTC, nota 7 .

${ }^{30}$ Ammat con Casa de Moneda (rol 1.328-92), 7-7-1992, RDJ 89, 2.5, 201 (comentario E. Soto Kloss, en TD cit., 109-114).

${ }^{31}$ Salgado con Municipalidad de El Tabo (rol P 80-93), 20-10-1993, RDJ 90, 2.5, 268-273.

${ }^{32}$ A simet cit., nota 25 . 
adultos impuesta a los comerciantes estacionados del sector señalado -establecidas en una resolución municipal que regula la actividad del comercio estacionario-, sólo constituye una forma de reordenamiento para el desempeño de esta modalidad de comercio dentro de la comuna y con ella se pretende según aparece de las actas de sesión acompañada a fs. 74, amparar a otro grupo de comerciantes, los establecidos, frente al aumento constante de artículos que se expenden en quioscos, hecho que perjudica al pequeño comerciante instalado que debe soportar una carga económica por detentar tal condición a la que no está sujeto el estacionado lo que distorsiona las reglas de una sana competencia" 33 .

\subsection{Licitación de espacios para taxis}

"La licitación efectuada por la Dirección de Aeronáutica Civil para la utilización de espacios destinados a la prestación de servicios de taxis en el aeropuerto Arturo Merino Benítez, en enero de 1994, no constituye un acto de regulación económica, sino una mera administración operativa de dicho aeropuerto, y tal licitación no implica que la Dirección desarrolle o participe en una actividad empresarial" 34 .

\subsection{Construcción de terminal pesquero}

"La construcción de la infraestructura para el funcionamiento de un terminal pesquero que sirva a necesidades urgentes y prioritarias de la Región Metropolitana, empleando en ella, fundamentalmente, una donación procedente de acuerdos de cooperación internacional celebrados hace largo tiempo confiando la realización de la tarea a una fundación sin fines de lucro, todo ello sin perseguir ganancias económicas alguna y disponiéndose luego a citar la operación o administración del referido terminal a particulares, no constituye desarrollo de, ni participación en, una actividad empresarial en los términos a que se refiere el artículo 19 № 21 de la Constitución Política. Por el contrario, se trata sólo del cumplimiento de finalidades sociales que son características de los entes públicos" $"$.

${ }^{33}$ Galleani Rodríguez cit, nota 13.

${ }^{34}$ Villalobos com Dirección General Aeronáutica Civil (rol 2.038-94), 9-9-1994, GJ 172, 92; en RDJ 91, 2.5, 208-212.

${ }^{35}$ Merza S.A. cit., nota 15. 


\section{CONCLUSIONES}

Del análisis somero de las principales sentencias dictadas en materia de recurso de amparo económico durante el quinquẹio de 1990 a 1995, puede concluirse que:

a) Existen a la fecha escasos fallos dictados, razón por la cual aún es prematuro obtener conclusiones de los mismos, dada la naturaleza de la referida acción.

b) La jurisprudencia analizada es, por añadidura, contradictoria en materias de especial importancia (por ejemplo, la relación entre el recurso de protección y el amparo económico, el ámbito de protección de la acción y, además, el alcance de la normativa aplicable al recurso de amparo y regulada en el Código de Procedimiento Penal). A pesar de que la Corte Suprema ya señaló que no es necesario dictar un Auto Acordado, sería razonable esperar que algunos aspectos pudieran ser regulados vía dicha normativa económica.

c) Se aprecia un exceso de formalismo, que ha significado que la mayoría de los fallos rechacen la acción por razones de carácter formal, sin entrar a analizar el fondo de la materia sometida a conocimiento de los tribunales.

d) Finalmente, es dable esperar que durante el próximo quinquenio los tribunales superiores de justicia empiecen a uniformar ciertos criterios con el objeto de permitir una mayor certeza jurídica, lo que debería, en gran parte, lograrse a través de la Sala Constitucional de la Corte Suprema. 
